Brit. J. vener. Dis. (1958), 34, 34.

\title{
GRANULOMA INGUINALE IN A JAMAICAN AND HIS WIFE*
}

\author{
BY \\ JACK BARROW \\ Department of Venereal Diseases, St. Thomas's Hospital, London
}

Knight and Fowler (1956) drew attention to the rising incidence of granuloma inguinale (venereum) in Great Britain. Conjugal examples of this condition are usually considered to be extremely uncommon and for this reason the following two case histories may be of interest.

\section{Case Reports}

A Jamaican aged 28, who had been living in England with his wife for 22 months, attended the Special Clinic at St. Thomas's Hospital with a penile lesion which, he stated, had been present for about 6 weeks. There had been an extra-marital risk some 7 weeks previously. He gave a history of childhood yaws and his Wassermann reaction and Price's precipitation reaction were positive, the latter to a titre of $1: 4$. On examination there was a red granulomatous, subpreputial lesion which was only partly revealed due to some degree of phimosis; The inguinal glands were not enlarged. There was no other genital abnormality and dark-ground examination failed to show Treponema pallidum. There were no signs of late syphilis and the cerebrospinal fluid and chest $x$ ray were normal. The positive serological tests were considered to be due to yaws. A diagnosis of granuloma inguinale was considered possible and circumcision-biopsy was carried out. Non-specific inflammation was reported and no Donovan bodies were seen. A course of penicillin for the yaws was started while he was in hospital for the circumcision.

Although he had been given a contact slip for his wife, she did not attend until about 2 months later, when she was found to have a granulomatous lesion on the left labium minus (Fig.1). The regional lymph glands were not enlarged. Dark-ground examination was negative for Treponema pallidum and her blood Wassermann reaction and Price's precipitation reaction

*Received for publication October 14, 1957. were negative. A scraping was taken from the lesion and a biopsy was also performed. The laboratory examined the slides of the scraping and reported the presence of Donovan bodies (Fig. 2).

Treatment.- She was given a course of tetracycline and the lesion rapidly healed. At this stage the nature of the husband's lesion was reconsidered and he also was given a course of tetracycline.

Sections from both patients together with a photograph of the smear were sent to Dr. Greenblatt in Augusta, Georgia, who was kind enough to examine them and reported as follows:

Study of the photographs of the smear impresses me with the fact that you are dealing with a case of granuloma inguinale. It appears that these organisms are of the immature type arranged in cystic spaces within the cytoplasm of the large monocytes.

I might say that; in the study of several hundred patients with granuloma inguinale at this institution. we found only a half-dozen or so instances of conjugal granuloma inguinale.

Dr. Greenblatt asked Dr. Pund, who did the basic work on the pathology of this disease, to study the tissue sections taken from both patients, and he reported as follows:

The architecture of the pathological changes is strongly suggestive of granuloma inguinale (venereum).

Although unable to demonstrate Donovan bodies in the tissue section, he agreed that the photograph of the smear was "highly suggestive of a cell parasitized with Donovan bodies".

\section{Summary}

Granuloma inguinale occurring in a Jamaican and his wife, both coloured, is reported. 


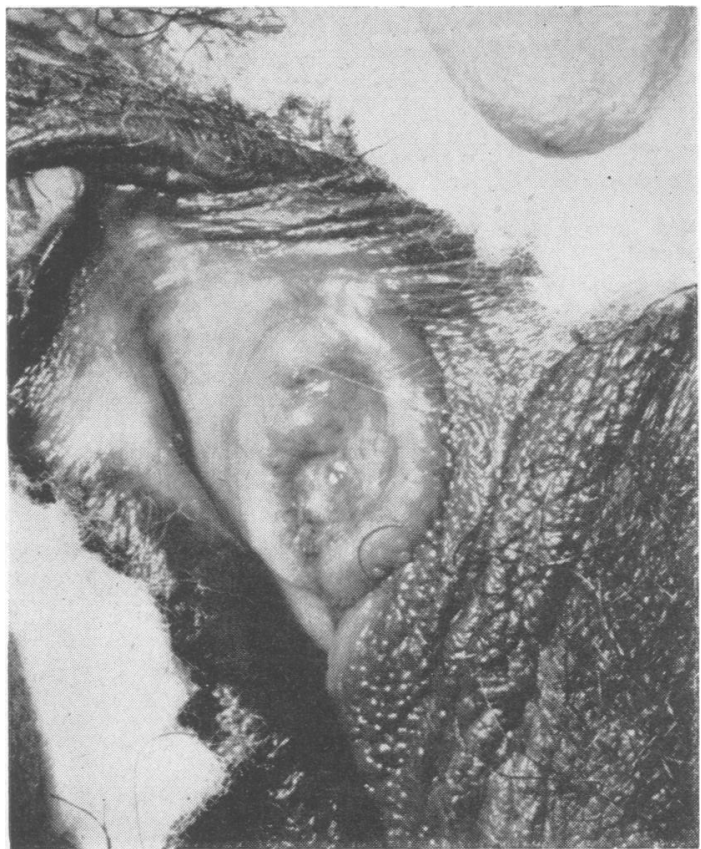

FIG. 1.-Granulomatous lesion of left labium minus.

My thanks are due to Dr. C. S. Nicol for permission to report these cases and for his helpful suggestions, and to Dr. W. D. Foster and Dr. J. McMillan of the Louis Jenner Laboratory, St. Thomas's Hospital, for their help with the pathology.

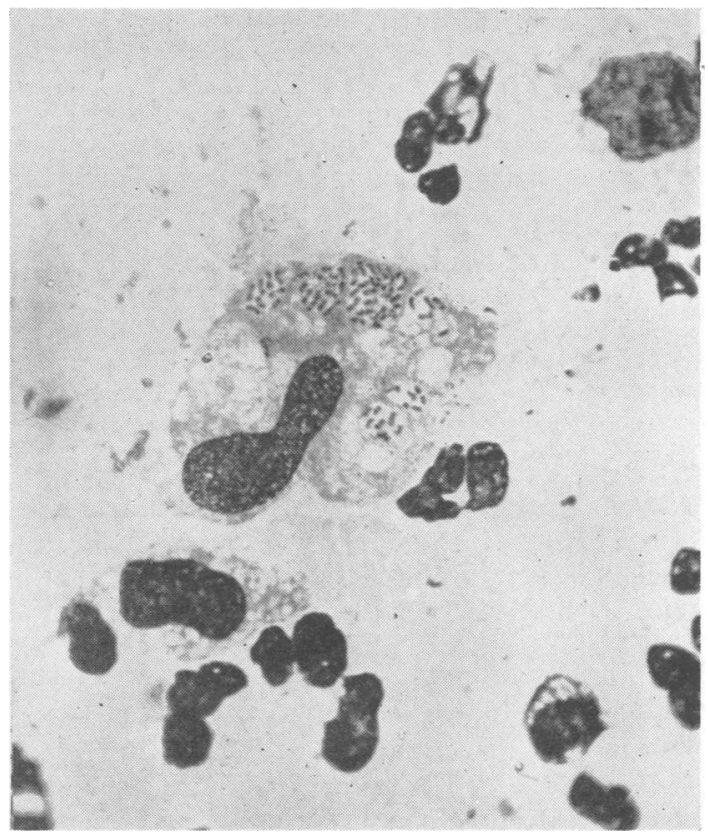

FIG. 2.-Photomicrograph of scraping from granuloma showing intracellular Donovan bodies.

\section{REFERENCES}

Greenblatt, R. B. (1956). Personal communication.

Knight, G. H., and Fowler, W. (1956). Brit. med. J., 2, 980.

Pund, E. R. (1956). Personal communication. 